\title{
Power Management of Hybrid Renewable System Integrated with Energy Storage System
}

\author{
Suganya B $\mathbf{S}^{\mathbf{1}}$, Arivalahan $\mathbf{R}^{2}$ \\ Student, Electrical and Electronics Engineering, Valliammai Engineering College, Chennai, India ${ }^{1}$ \\ Associate Professor, Electrical and Electronics Engineering, Valliammai Engineering College, Chennai, India ${ }^{2}$
}

\begin{abstract}
Recent year's renewable energy sources plays important role in power generation system. Due to intermittent nature of renewable sources such as wind and solar, the energy storage systems (ESS) are required in renewable power generating systems. This paper deals with power management of the ESS based on hydrogen storage (electrolyzer, hydrogen tank, fuel cell) and battery integrated in hybrid renewable energy systems. The supervisory controller based on neuro-fuzzy inference system determines the power that must be generated by or stored in hydrogen and battery. The solar photovoltaic panels and wind turbine used as primary energy sources. The dc-dc converters connect all the energy sources to central dc bus. The model for each process component is developed in a MATLAB/Simulink environment.
\end{abstract}

Keywords: Hybrid system, ANFIS, energy storage system, Energy management system (EMS).

\section{INTRODUCTION}

One of the major concerns in power sector is the day-today increasing power demand but there is unavailability of enough resources to meet the power demand using the conventional energy sources. Studies for alternative energy sources wind, solar have gained significance since it is more difficult to provide the increasing energy needs of the world from fossil fuels in both economic and safe ways and due to recently developing public conscience in order to save the environment. The use of these hybrid renewable energy systems (HRES) presents some advantages over larger power plants, such as environmental-friendly, high power quality, uninterruptible service, cost savings, on-site generation, and expandability [1], [2].

Because of their intermittent nature, wind and solar energy resources in a given area can be complementary on a daily and/or seasonal basis, a support energy source is needed to increase the degree of controllability and operability of the HRES [3]. Traditionally, this function is performed by an ESS such as battery and hydrogen system (i.e., FC, electrolyzer and hydrogen storage tank) [4].It has been shown that a typical hybrid renewable energy system (HRES) combines several renewable energy sources, energy storage system and power conditioning equipment can improve the system's performance [5].

All renewable sources and ESS are connected together to a central dc bus by means of power converters. These converters are designed to deliver energy from the energy sources, ensuring stable, sustainable and reliable operation [8]. The dc-dc and ac-dc power converters interface the renewable sources and ESS to a dc bus, and dc-ac voltage source inverters are in charge of delivering the active and reactive power to the grid. In HRES the supervisory control system is responsible for determining the reference power that must be generated by/stored in the ESS. Then the converters associated with the renewable sources and EES are controlled, so that the energy sources work as required by the supervisory control system [6], [7].

The importance of a control strategy for the optimal operation of the photovoltaic (PV)/hydrogen/battery systems has been shown previously [9]. The outputs from the various generation sources of a hybrid energy system need to be coordinated and controlled to realize its full benefit. Thus, development of suitable power management that ensures meeting the customer load demand despite the intermittent nature of RE sources is an integral part of ensuring the system's reliability and achieving operational efficiency [10].

Classical control techniques based on state machine controllers or PI controllers require exact mathematical model of the system and are very sensitive to parameter variations [15]. Intelligent control techniques such as artificial neural networks, fuzzy logic, neuro-fuzzy are more efficient and robust than classical techniques, since they do not require an exact model of the system. Among the neuro-fuzzy systems, adaptive neuro-fuzzy inference system (ANFIS) is faster in convergence when compared to the other neuro-fuzzy models.

In the existing literature, a large-scale integration of wind, PV was analysed and grid connection was discussed in [13]. In [14] a detailed dynamic model, design and simulation of wind/FC/UC based hybrid system was described. The optimal integration of hydrogen storage with RE sources and the power management of such systems have also received considerable attention [16], [17]. The comprehensive model for the wind/PV/electrolyzer/FC system and a power management tool that utilizes adaptive model predictive control (MPC) is described in [20]. 

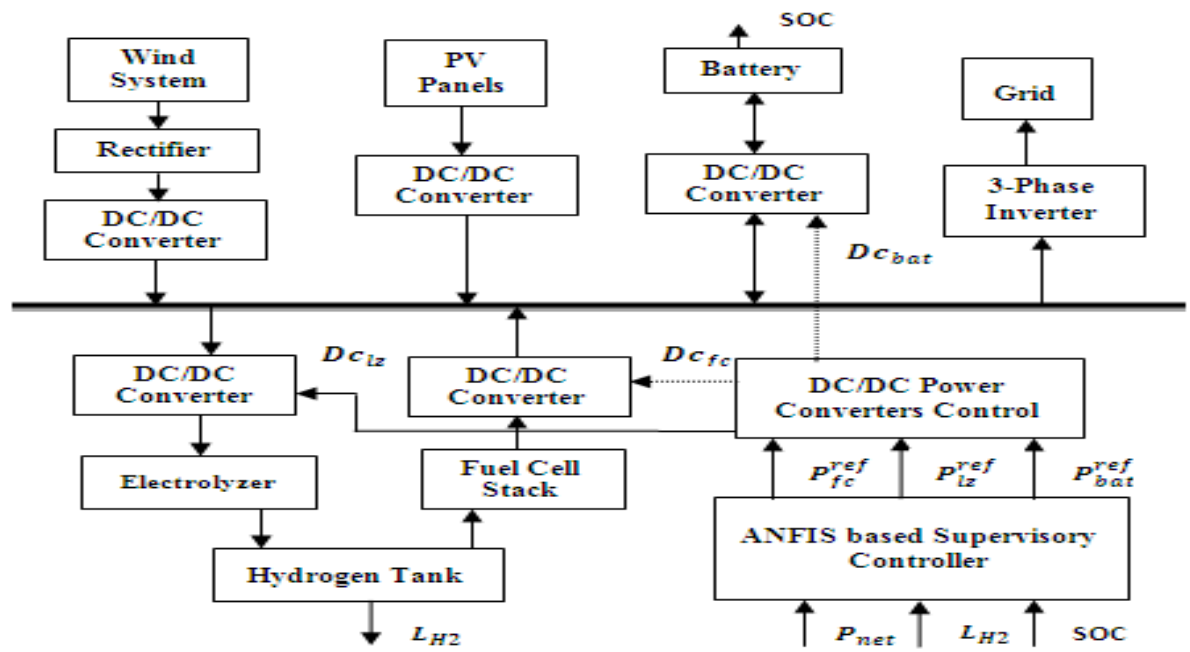

Fig. 1. DC coupled grid connected hybrid system.

\section{HYBRID SYSTEM}

The hybrid system under study is the dc coupled grid connected system that composed of WT and PV panels (renewable and primary energy sources) and hydrogen subsystem and battery (ESS). All of them use dc-dc power converters in order to connect them to a central dc bus. The whole system is connected to a grid by a three-phase inverter. In this system, the renewable sources are generating whenever there is wind or solar radiation. When possible, renewable energy is stored in the battery and/or in the form of hydrogen by using the electrolyzer and this stored energy is recovered to support the renewable production when necessary [18], [19]. This is performed by ANFIS based supervisory controller by taking in to account the power demanded by the grid, the available power, the hydrogen tank level and battery state of charge (SOC). Fig. 1 shows the block diagram of grid connected hybrid system.

\section{A. Wind Energy System}

The wind energy conversion system consists of wind turbine to capture energy in the wind, a drive train to speed up the rotational speed of the shaft, and a generator to convert the mechanical energy into electrical energy [20]. The generation systems consist of a three phase PSMG represented by models included SimPowerSystems [11]. The buck-type dc-dc power converter, which connects the wind turbine to the hybrid system dc bus, is controlled by tip speed ratio (TSR) maximum power point tracking (MPPT) [12]. This MPPT control modifies the duty cycle of the wind turbine dc-dc converter, which produces a variation of its rotational speed. TSR method tries to modify the rotational speed of generator so as to maintain an optimum TSR.

\section{B. Solar Photovoltaic Panels}

A photo voltaic system directly converts sunlight into electricity. The basic device of PV system is PV cell. A single diode model, which is composed of a current source and a parallel diode with two resistances is used to represent each PV panels [10]. A dc-dc power converter controlled by a MPPT controller adapts the PV output voltage to the dc bus voltage. The MPPT controller generates the duty cycle of the PV converter to move the $\mathrm{PV}$ voltage to voltage that corresponds to the maximum power point (MPP). In this study incremental conductance algorithm is used as MPPT algorithm to generate the duty cycle of the controller.

\section{Hydrogen Subsystem}

The hydrogen subsystem is composed of PEM electrolyzer, hydrogen tank and PEM fuel cell. The connection of $\mathrm{FC}$ and electrolyzer to the $\mathrm{dc}$ bus is performed by using boost-type unidirectional converters. The electrolysis of water using cells with a polymer electrolyte membrane (PEM) is a very efficient method of producing hydrogen. It is modelled by a resistance, in which the power needed to produce hydrogen is consumed [20]. Faraday's law is used to calculate the hydrogen produced, depending to the electrical current in resistance [15].

The hydrogen produced by the electrolyzer is stored in the hydrogen tank. In the hydrogen tank model, the hydrogen available in the tank is obtained from the rate of incoming and outgoing hydrogen, taking into account the ideal gas equation [16]. The PEM FC uses the hydrogen available in the tank in order to produce electrical energy [20]. The PEM FC model is built by utilizing the models included in [11].

\section{Battery}

In this study the hybrid system uses a lead-acid battery. This type of battery is least expensive storage battery for many applications. This battery is modelled by a resistance in series with a variable voltage source. The inputs of the model are the electrical power, ambient temperature and mean value of the discharge current. SOC is the output of the battery model [21]. 


\section{III.Power Management Using Neuro-Fuzzy CONTROLLER}

FL and ANNs are complementary technologies in the design of intelligent control systems [22]. Neuro-fuzzy systems combine the inference ability of fuzzy logic like a human and the learning and parallel data processing abilities of ANNs. With these systems, the development time is reduced and the accuracy of the fuzzy model is improved.

The Adaptive-Neuro Fuzzy Inference System is a hybrid system that combines the potential benefits of both the methods Artificial Neural Network (ANN) and fuzzy logic (FL) developed by Jang in 1993 [23]. This system has been employed in numerous modelling and forecasting problems. ANFIS starts its functionality with the fuzzification of input parameters defining the membership function parameters and design of fuzzy IF-THEN rules, by effectively employing the learning capability of ANN for automatic fuzzy rule generation and self adjustment of membership functions.

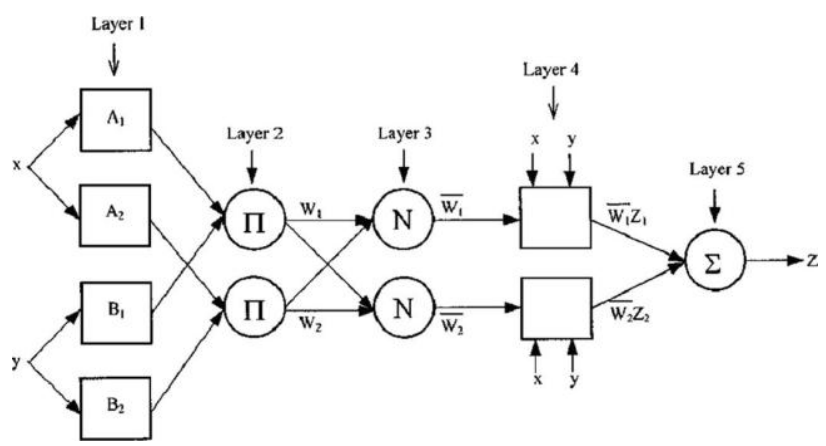

Fig. 2: Typical architecture of ANFIS

A typical architecture of an ANFIS [22] is shown in Fig. 2, in which a circle indicates a fixed node, whereas a square indicates an adaptive node. It presents a multi-layered feed-for-ward network, in which each layer has a particular function on the input signals. In this example, ANFIS has two inputs $(x, y)$ one output $(f)$, with five layers and two rules are given below:

Rule 1: IF $x=A_{1}$ and $y=B_{1}$ THEN $f_{1}=p_{1}+q_{1}+r_{1}$ Rule 2: IF $x=A_{2}$ and $y=B_{2}$ THEN $f_{2}=p_{2}+q_{2}+r_{2}$

- Layer 1: Membership function of inputs (x, y).

- Layer 2: Represents the firing strength $\left(w_{1}, w_{2}\right)$ of each rule.

- Layer 3: Normalized firing strength of each rule.

- Layer 4: Linear functions $\left(f_{1}, f_{2}\right)$ that are functions of input signals.

- Layer 5: Overall output.

MF parameters must be tuned by the training data. The ANFIS based control was implemented by using the Fuzzy Logic Toolbox of MATLAB.

\section{A. ANFIS Supervisory Power Control}

This system controls the operation of ESS. The ANFISbased supervisory control system is responsible for Copyright to IJIREEICE determining the power that must be generated by/stored in the hydrogen (FC/electrolyzer) and battery. Fig. 3 shows the overall configuration of the ANFIS- based supervisory control system. ANFIS control system has three inputs, the battery SOC, the hydrogen tank level, and the net power, $P_{\text {net }}$ (difference between the power demanded by the grid $P_{d e m}$ and the renewable power generated by the WT and PV panels, $\left.P_{r w}\right)$. It has one output, the battery reference power. The hydrogen reference power (FC and electrolyzer) is calculated as the difference between the net power and the battery reference power.

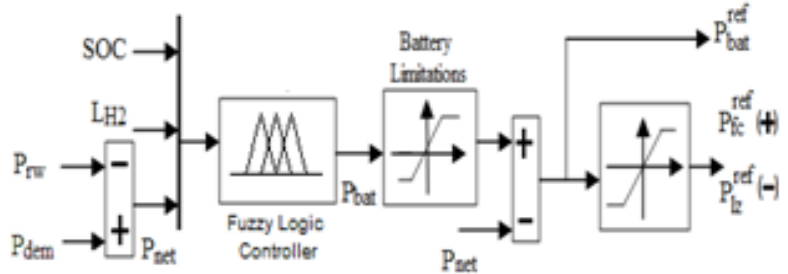

Fig. 3: ANFIS-based supervisory control system.

In the case of $P_{\text {net }}=0$ there is sufficient power generated from renewable sources to meet the demand with neither excess nor deficit of energy. The electrolyzer and fuel cell activation and deactivation are based on the $P_{\text {net }}$ value which is calculated in each sampling interval. When there is excess power generated $\left(P_{n e t}>0\right)$, the electrolyzer is activated. On the other hand, when there is a deficit in power generation $\left(P_{n e t}<0\right)$, the fuel cell stack is activated to consume previously stored hydrogen and convert it to electricity.

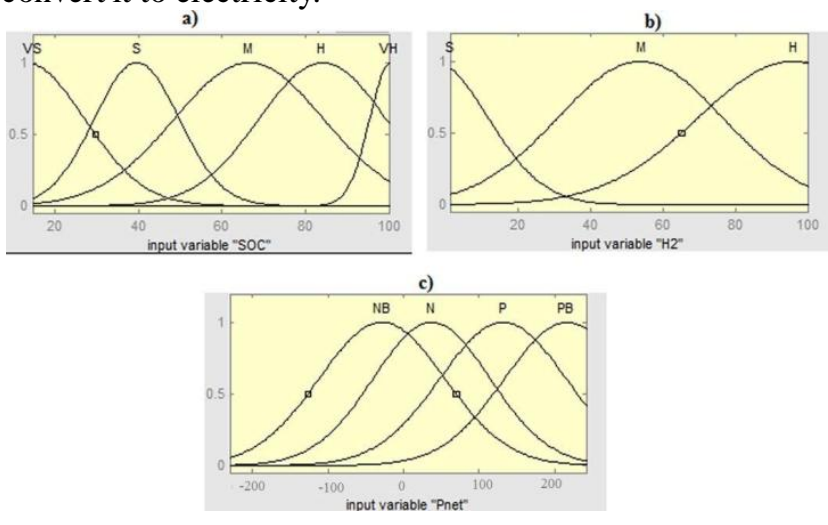

Fig. 4: Membership functions VS ANFIS input variables.

Fig. 4 shows the bell shaped MF used in this work. The net power uses four MF: negative big (NB), negative $(\mathrm{N})$, positive $(\mathrm{P})$, and positive big $(\mathrm{PB})$. The hydrogen tank level presents three MFs: small (S), medium (M) and high (H). Finally, the battery SOC has five MFs: very small (VS), small (S), medium (M), high (H), and very high (VH). To define these MFs, 1600 training and testing data were used. The final error, defined as the root-meansquare difference between the current and desired outputs of the battery power, was 0.3318 . The battery SOC and hydrogen tank level varied between 0 and $100 \%$. 


\section{B. DC-DC Power Converters Control}

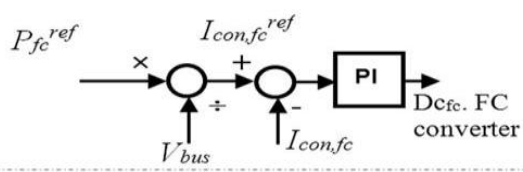

b)
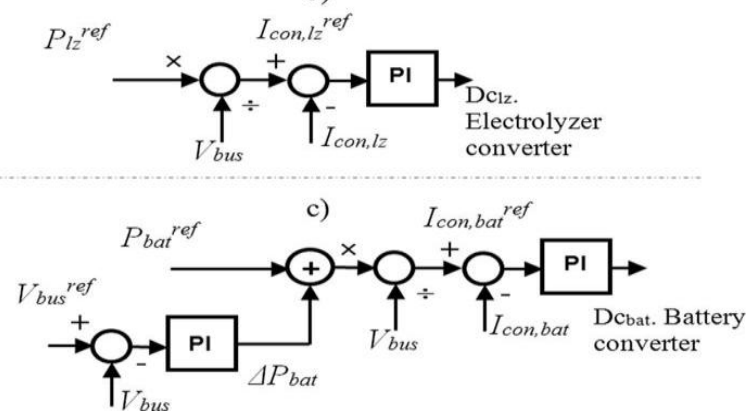

Fig. 5: Control loops applied to dc-dc power converters. (a)FC converter. (b) Electrolyzer converter. (c) Battery.

The dc-dc power converters allow the battery, electrolyzer, and FC to adjust the power to the reference value defined by the supervisory control system. Fig. 5 shows the control loops applied to the dc-dc power converters. In the case of the FC and electrolyzer, the reference current of their $\mathrm{dc}-\mathrm{dc}$ power converters is obtained by dividing the reference power by the dc bus voltage. The duty cycle of these converters is defined from a PI controller for the current control loop. The battery converter allows controlling the battery power, and the dc bus voltage to the rated value. The battery reference power defined by the supervisory control system is modified by the output of a PI controller for the dc bus voltage control loop.

IV.SimULATION RESUlTS
TABLE I
HYBRID System COMPONENTS RATING
\begin{tabular}{|c|c|}
\hline Component & Rating \\
\hline PV panels & $1.6 \mathrm{KW}$ \\
\hline Wind turbine & $1.5 \mathrm{KW}$ \\
\hline Electrolyzer & $0.48 \mathrm{KW}$ \\
\hline Fuel cell & $1.26 \mathrm{KW}$ \\
\hline Battery & $24 \mathrm{~V}, 6.5 \mathrm{Ah}$ \\
\hline
\end{tabular}

The proposed hybrid system model consisting of the previously described components was implemented using the MATLAB and Simulink software. This simulation results are used to check the right performance of ANFISbased supervisory control system in order to satisfy the power demanded by the grid and control the battery SOC, hydrogen level and battery, FC and electrolyzer power.

The PV and wind turbine dc-dc converters incorporate a MPPT controller, so that the renewable energy sources are generating the maximum available power in every period.
The controls of PV and wind turbine are considered independent of supervisory control systems. Power generated by primary energy sources are stored in ESS or directly given to the grid based on the needs. Ratings of the hybrid system components are shown in Table. 1. Fig. 9 Shows the dc bus voltage waveform.

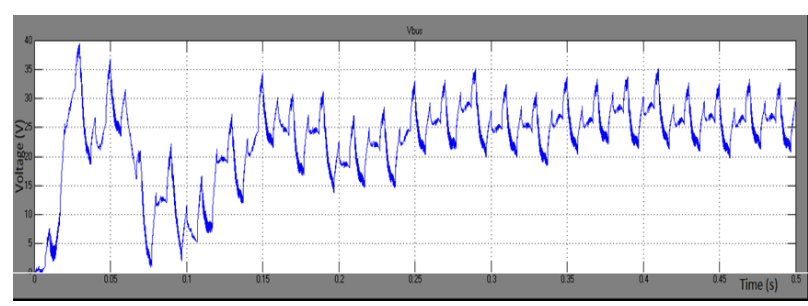

Fig. 6: DC Bus voltage waveform

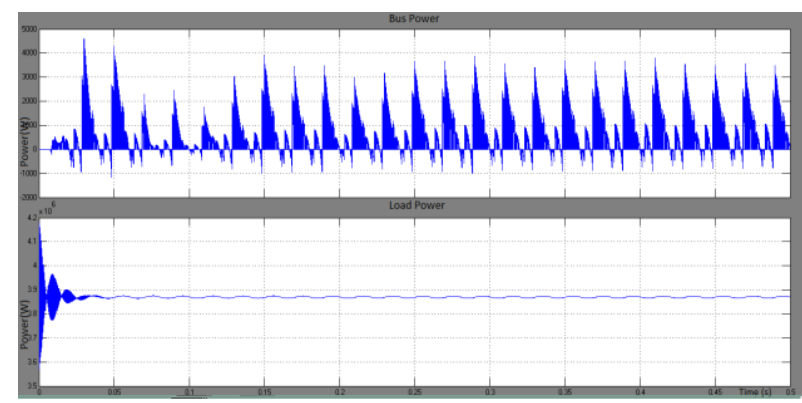

Fig. 7: (a) Renewable power generated. (b) Power demanded by the grid.

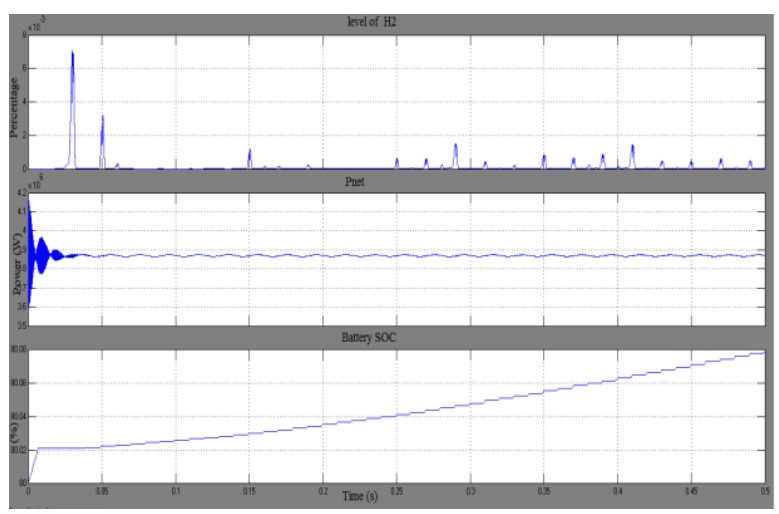

Fig. 8: (a) Level of hydrogen tank. (b) Net power. (c) Battery SOC.

Furthermore, Fig. 7 Shows the renewable (WT, PV) power generated and power demanded by the grid. When the demanded power is almost equal to the maximum available power, the battery and FC help to the primary energy sources by generating extra power. On the contrary, when the demanded power is very small compared with the maximum available power, the power excess is stored in the battery or used in the electrolyzer to produce hydrogen, and then, the battery SOC and hydrogen tank level increase. Fig. 8 shows the level of hydrogen tank, the net power and battery SOC. 


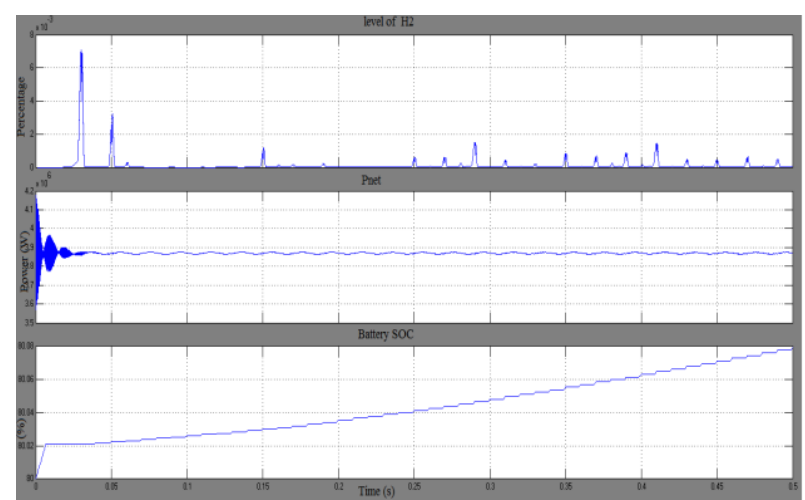

Fig. 9: Battery, FC and electrolyzer power with ANFISbased supervisory control system.

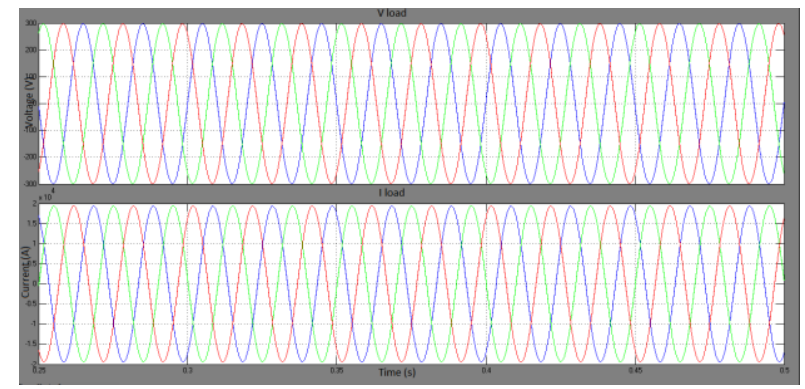

Fig. 10: Load voltage and current waveforms

Fig. 9 shows the maximum power available in the battery and hydrogen. The power used in the electrolyzer to produce hydrogen is equal to the power generated from fuel cell in the same amount of hydrogen. In the case of the battery, the supervisory control system avoids a SOC under $20 \%$. If the sign of the power is positive, the battery is charged. The battery is discharged if the sign of the power is negative. Fig.10. shows the load voltage and current waveforms. The output of the supervisory control system reference power values used in the dc-dc converters control, produce suitable duty cycle (Dc) values for converters of electrolyzer, fuel cell and battery.

\section{Conclusion}

A detailed model for a grid connected hybrid energy system with wind turbine and solar energy conversion, battery, electrolyzer, fuel cell, and hydrogen storage components was developed in the MATLAB/Simulink environment. An adaptive neuro-fuzzy supervisory controller for proper power management was implemented. The ANFIS controller was designed for optimal operation of the electrolyzer, fuel cell and battery. The controller performance showed significant improvement in the utilization of both components. The renewable energy sources operate at the maximum power point, independently of energy management system. Therefore, the EMS is responsible for managing the operation of the ESS (battery and hydrogen system).

\section{REFERENCES}

[1] S. S. Dihrab and K. Sopian, "Electricity generation of hybrid PV/wind systems in Iraq," Renew. Energy, vol. 35, no. 6, pp. 1303-1307, 2010.
[2] Alsayegh $\mathrm{O}$, Alhajraf S, Albusairi H, Grid-connected renewable energy source systems: challenges and proposed management schemes. Energy Convers Manage 2010;51(8):1690-3.

[3] M. H. Nehrir, C. Wang, K. Strunz, H. Aki, R. Ramakumar, J. Bing, Z. Miao, and Z. Salameh, "A review of hybrid Renewable/Alternative energy systems for electric power generation: Configurations, con- trol, and applications," IEEE Trans. Sustain. Energy, vol. 2, no. 4, pp. 392-403, Oct. 2011.

[4] M. Santarelli, M. Cali, and S. Macagno, "Design and analysis of stand- alone hydrogen energy systems with different renewable sources," Int. J. Hydrogen Energy, vol. 29, no. 15, pp. 1571-1586, Dec. 2004.

[5] D. Nelson, M. Nehrir, and C. Wang, "Unit sizing and cost analysis of stand-alone hybrid wind/PV/fuel cell power generation systems," Renew. Energy, vol. 31, no. 10, pp. 1641-1656, 2006.

[6] F. Valenciaga and P. F. Puleston, "Supervisor control for a standalone hybrid generation system using wind and photovoltaic energy," IEEE Trans. Energy Convers., vol. 20, no. 2, pp. 398405, Jun. 2005.

[7] S. Jiang, W. Wang, H. Jin, and D. Xu, "Power management strategy for microgrid with energy storage system," in proc. 37th Annu. Conf. IEEE Ind .Electron. Soc., pp. 1524-1529.

[8] S. Kim, J. H. Jeon, C. H. Cho, J. B. Ahn, and S. H. Kwon, "Dynamic modeling and control of a grid-connected hybrid generation system with versatile power transfer," IEEE Trans. Ind. Electron., vol. 55, no. 4, pp. 1677-1688, Apr. 2008

[9] Ø. Ulleberg, "The importance of control strategies in PV-hydrogen systems," Solar Energy, vol. 76, nos. 1-3, pp. 323-329, Jan.-Feb. 2004.

[10] J. L. Bernal-Agustin and R. Dufo-Lopez,"Simulation and optimization of stand-alone hybrid renewable energy systems," Renew. Sust. Energ. Rev., vol.13, no. 8, pp.2111-2118, Oct.2009.

[11] SimPowerSystems, Reference. Hydro-Quebec, MathWorks, Inc., Natick, MA, USA, 2012.

[12] Shrikant S. Mali, B. E. Kushare, "MPPT Algorithms: Extracting maximum power from wind turbines," International Journal of innovative research in electrical, electronic, instrumentation and control engineering, vol.1, issue.5, Aug 2013.

[13] Lund H. "Large-scale integration of optimal combinations of PV, wind and wave power into the electricity supply," Renewable Energy 2006;31(4):503-15.

[14] Onar OC, Uzunoglu M, Alam MS, "Dynamic modeling, design and simulation of a wind/fuel cell/ultra-capacitor based hybrid power generation system. Journal of Power Source 2006;161(1):707-22.

[15] M. Uzunoglu, O. C. Onar, and M. S. Alam, "Modelling, control and simulation of a PV/FC/UC based hybrid power generation system for stand-alone applications," Renew. Energ., vol.34, no. 3, pp. 509-520, Mar. 2009.

[16] B. Panahandeh, J. Bard, A. Outzourhit, and D. Zejli, "Simulation of $\mathrm{PV}$-wind hybrid systems combined with hydrogen storage for rural electrification," Int.J. Hydrogen Energ., vol.34, no.6, pp. 41854197, Mar.2011.

[17] J. P. Torrenglosa, P. Garcia, L. M. Fernandez, and F. Jurado, "Predictive control for the energy management of fuel cell-batterysupercapacitor tramway," IEEE Trans. Ind. Inf.,vol. PP, no. 99, pp. 1-9, 2013.

[18] P. Garcia, L. M. Fernandez, F. Jurado, and C. A. Garcia, "Comparative study of PEM fuel cell models for integration in propulsion systems of urban public transport," Fuel Cells, vol. no. 6, pp.1024-1039, Dec. 2010.

[19] M. Trifkovic, M. Sheikhzadeh, K. Nigim, and P. Daoutidis, "Hierarchical control of a renewable hybrid energy system," in Proc. 51st IEEE Annu. Conf. Decision Control, Dec. 2012, pp. 6376-6381.

[20] Milana Trifkovic, Mehdi Sheikhzadeh, Khaled Nigim, and Prodromos Daoutidis, "Modelling and control of a renewable hybrid energy system with hydrogen storage," IEEE trans. Control. Sys. Tech, vol. 22, no. 1, Jan 2014.

[21] O. Tremblay and L. A. Dessaint, "Experimental validation of a battery dynamic model," world Electr. Veh. J., vol. 3,no. 1, pp. 1-10, 2009.

[22] J.-S. R. Jang, "ANFIS: Adaptive-network-based fuzzy inference system," IEEE Trans. Syst. Man Cybern., vol. 23, no. 3, pp. 665685, May/Jun. 1993.

J.-S. R. Jang and C. T. Sun, "Neuro-fuzzy modelling control," Proc. IEEE, vol. 83, no. pp. 378-406, Mar. 1995. 


\section{BIOGRAPHIES}

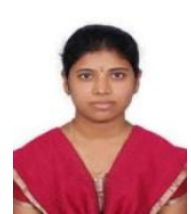

B. S. Suganya received the B.E. degree in electrical and electronics engineering from Panimalar Institute of Technology, Chennai, India, in 2013 and she is currently pursuing the M.E. degree in Powers Systems Engineering in Valliammai Engineering College, Chennai, India. Her major fields of interest are power systems, renewable energy, fuzzy systems, neural networks, ANFIS control.

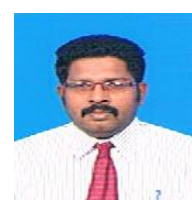

R. Arivalahan obtained his BE degree in Instrumentation and Control Engineering from the University of Madras in 1999 and obtained his ME degree in Process Control and Instrumentation from Annamalai University in 2002. He obtained his PhD Degree from Anna University, Chennai in the Department of Electrical and Electronics Engineering in April 2014.

His area of research interest is the advanced controller concepts with fuzzy logic controller, neural networks, adaptive controller and genetic algorithm. Currently, he is working as an Associate Professor in Electrical and Electronics Engineering at Valliammai Engineering College, SRM Nagar, Kattankulathur, Chennai. 